\title{
Short term haemodynamic effects of converting enzyme inhibition before and after eating in patients with moderate heart failure caused by dilated cardiomyopathy: a double blind study
}

Cardiac Division Department of Medicine, Hudding University Hospital, Huddinge, Sweden

B Herrlin

C Sylvén

O Nyquist

O Edhag

Correspondence to

Dr Bo Herrlin, Department of Medicine, Huddinge Hospital, S-141 86 Huddinge, Sweden.

Accepted for publication 20 July 1989

\author{
Bo Herrlin, Christer Sylvén, Olof Nyquist, Olof Edhag
}

\begin{abstract}
The haemodynamic changes that follow a meal can mimic the response to a vasodilator drug. To avoid overestimating the beneficial effects of treatment in uncontrolled studies, measurements of haemodynamic function are usually performed with patients in the fasting postabsorptive state. But such recordings are not representative of the resting patient during daily life. In this double blind placebo controlled study the short term haemodynamic effects of enalapril were assessed during 12 hours in 19 patients with moderate heart failure caused by dilated cardiomyopathy. The patients ate lunch and dinner and were studied in the absorptive and postabsorptive phases. In the placebo group systemic vascular resistance, mean arterial pressure, and the rate-pressure product fell significantly (5-16\%) after lunch. Four hours after lunch the haemodynamic function had returned to baseline-that is the postabsorptive state. Enalapril, accentuated the haemodynamic effects during the absorptive state producing a larger post-prandial fall in mean arterial blood pressure and rate-pressure product and changes in the absorptive phase were maintained into the postabsorptive phase. Pulmonary wedge pressure fell significantly after treatment with enalapril. These overall changes during the study period indicated that enalapril reduced the preload and afterload on the heart-over and above the reduction produced by eating.

These findings suggest that the effects of enalapril given at rest to patients with moderate heart failure unload the heart and enhance the reduction of afterload induced by meals.
\end{abstract}

The haemodynamic effects of drugs are usually studied in fasting patients. Such recordings do not represent the effects in resting patients who are eating normally. Splanchnic vasodilatation in the absorptive phase may change central haemodynamic function ${ }^{1-3}$ by reducing the systemic afterload.

Activation of the renin-angiotensin system, which increases systemic vascular resistance, ${ }^{4}$ is an important compensatory mechanism in treated heart failure. Angiotensin-converting enzyme inhibitors cause systemic vasodilatation and reduce the load on the heart. ${ }^{56}$ In heart failure such drugs may enhance the haemodynamic effects seen in the absorptive phase.

We investigated the complex haemodynamic effects of enalapril and eating and absorption in a double blind, controlled, randomised study in a homogeneous group of patients with treated moderate heart failure caused by dilated cardiomyopathy. We studied the angiotensinconverting enzyme inhibitor, enalapril, because its bioavailability was reported not to be influenced by food intake ${ }^{7}$ and because a single oral dose gives therapeutic serum concentrations throughout a 12 hour study period.

\section{Patients and methods}

\section{PATIENTS}

We studied 19 patients (16 men and three women (41-62 years old (mean (SD)) 51 (6) years)), with moderate heart failure caused by dilated cardiomyopathy, which was treated with digoxin and frusemide. None of the patients had oedema and all had been clinically stable for at least two weeks. Inclusion criteria were an echocardiographically determined left ventricular end diastolic dimension of $>30$ $\mathrm{mm} / \mathrm{m}^{2}$, a left ventricular shortening fraction of $<20 \%$, and an exercise capacity of $>$ stage III and < stage IX according to a revised Naughton protocol. ${ }^{8}$ We excluded patients with primary valve disease, suspected ischaemic heart disease, or congenital valve disease; those taking concomitant vasodilating agents; and those with right sided heart failure caused by pulmonary disease. The study protocol was approved by the local ethics committee. All patients gave their informed consent before entering the study.

\section{PROTOCOL}

The patient was admitted to hospital and served meals containing a known concentration of sodium. The daily doses of digoxin and frusemide remained unchanged. On the first day the blood volume was determined and echocardiography, a chest $x$ ray, and an exercise test were performed. Serum albumin labelled with iodine-131 was used to measure the total blood volume.

Echocardiography was performed on patients in the left lateral position (ATL Mark III, $13 \mathrm{~mm}$ and $3 \mathrm{MHz}$ transducer). The transducer position and cardiographic gain were adjusted to obtain optimal recordings of 
left ventricular dimensions in the short axis. We measured the left ventricular end diastolic diameter (LVEDD) and left ventricular end systolic diameter (LVESD). ${ }^{9}$ The mean value for five consecutive beats was calculated. The left ventricular shortening fraction was derived from the difference between LVEDD and LVESD divided by LVEDD.

Cardiac volume was measured radiologically by Jonsell's method. ${ }^{10}$ Patients performed the exercise test sitting on an electrically braked ergometer. The load was increased every two minutes according to a modified Naughton protocol $^{8}$ :

Stage I II III IV V VI VII VIII IX W $\quad \begin{array}{lllllllll}10 & 20 & 30 & 50 & 70 & 90 & 110 & 130 & 150\end{array}$

The patients exercised until limiting symptoms developed - that is dyspnoea or fatigue or both.

On the third day at 5.30 am the patient was given a light breakfast and his or her daily dose of digoxin and frusemide. The right ventricle was catheterised at $8 \mathrm{am}$. A triple lumen balloon tipped thermodilution catheter (Edwards Laboratory, USA) was introduced via an antecubital or femoral vein under fluoroscopic guidance and was used to measure the right atrial, pulmonary arterial, and pulmonary capillary wedge pressures. A polyethylene arterial catheter was introduced into the brachial or femoral artery to measure systemic pressure. The patient was placed in bed and transported to the coronary care unit for haemodynamic monitoring for 12 hours after two hours of rest. We used HewlettPackard transducers (HP 1290) and a HewlettPackard patient monitoring system (Model HP 78342A). All haemodynamic measurements were done by the same physician $(\mathrm{BH})$. The measurements of haemodynamic function were made with the zero reference level at the midaxillary line with the patient supine and the bed in a horizontal position. Before each haemodynamic measurement we checked that the zero transducer pressure was the same as atmospheric pressure; calibration scales were displayed electronically. Cardiac output was measured by a bedside cardiac output computer (Cardiac Computer, Edwards Laboratories, model 9520) with the use of an iced injectate. Heart rate was derived from a continuously recorded electrocardiogram. The patients were randomised double blindly to enalapril $10 \mathrm{mg}$ or placebo, and drugs were given at 0 hours. Recordings were made at 0,1 , $2,3,4,5,6,8$, and 12 hours. The patients ate portions of meals of their own choice after one and five hours. Snacks and coffee or tea were not allowed but water was available.

Serum concentrations of enalaprilat were measured by radioimmunoassay. ${ }^{11}$

\section{ANALYSES}

Mean right atrial pressure (RAP), mean pulmonary artery pressure (MPAP), mean pulmonary capillary wedge pressure (PCWP), systolic systemic arterial pressure (SAP), and mean systemic arterial pressure (MAP) were measured by electronic integration. The mean of at least six determinations was calculated; each was the average for 12 seconds. Cardiac output (CO) was determined in triplicate. Heart rate (HR) was determined for one minute. Derived haemodynamic variables were calculated as follows:

$$
\begin{gathered}
\text { Cardiac index }(\mathrm{CI})\left(1 / \mathrm{min} / \mathrm{m}^{2}\right)=\mathrm{CO} / \\
\text { body surface area }
\end{gathered}
$$

Stroke volume index $(\mathrm{SVI})\left(\mathrm{ml} /\right.$ beat $\left./ \mathrm{m}^{2}\right)=$ $\mathrm{CI} / \mathrm{HR}$

Systemic vascular resistance (SVR) (dyn.s. $\mathrm{cm}^{-5}$ ) $=80 \times($ MAP-RAP $) / C O$

Pulmonary vascular resistance (PVR) $\left(\right.$ dyn.s.cm $\left.{ }^{-5}\right)=80 \times($ MPAP-PCWP $) / C O$

Rate-pressure product (RPP) (beats. $\mathrm{mm} \mathrm{Hg}$ $\min )=\mathrm{HR} \times \mathrm{SAP}$

\section{STATISTICAL ANALYSIS}

Values are given as means (SD). Unpaired $t$ tests were used to evaluate differences between two groups. Multiple comparisons of repeated measurements were tested by analysis of variance and Fisher's protected least square significance test. A p value of $<0.05$ was regarded as significant.

\section{Results}

Ten patients were randomly allocated to enalapril and nine to placebo. One patient became symptomatically hypotensive six hours after administration of enalapril and was successfully treated with an infusion of saline. This patient was excluded from further study. The remaining 18 patients completed the study without complications.

Table 1 shows the clinical characteristics and non-invasive findings. The mean heart volume and the daily dose of frusemide were significantly larger in the group receiving enalapril than in the placebo group ( $p<0.05)$. Other characteristics were similar in the two groups. All patients had concentrations of serum sodium within the normal range.

There were no significant differences in haemodynamic variables between the two groups at baseline (0 hour, table 2 ).

Table 1 Clinical characteristics, non-invasive findings,

\begin{tabular}{|c|c|c|c|}
\hline & $\begin{array}{l}\text { Placebo group } \\
(n=9)\end{array}$ & $\begin{array}{l}\text { Enalapril group } \\
(n=9)\end{array}$ & p value \\
\hline $\begin{array}{l}\text { Age }(y r) \\
\text { Sex }(F / M) \\
\text { Duration of symptoms }\end{array}$ & $\begin{array}{l}53 \\
2 / 7\end{array}$ & ${ }_{1 / 8}^{50}$ & $\begin{array}{l}\text { NS } \\
\text { NS }\end{array}$ \\
\hline $\begin{array}{l}\text { (mnth) } \\
\text { Frusemide dosage }\end{array}$ & $21 \quad(12)$ & $41 \quad(30)$ & NS \\
\hline $\begin{array}{l}\text { (mg/day) } \\
\text { ECG (AF/SR) } \\
\text { Exercise duration (s) }\end{array}$ & $\begin{array}{l}98 \\
2 / 7 \\
701\end{array}$ & $\begin{array}{l}158(65) \\
3 / 6 \\
692(173)\end{array}$ & $\begin{array}{l}<0.05 \\
\text { NS } \\
\text { NS }\end{array}$ \\
\hline $\begin{array}{l}\text { Chest } x \text { ray, heart } \\
\text { volume }\left(\mathrm{ml} / \mathrm{m}^{2}\right)\end{array}$ & $712(144)$ & $872(168)$ & $<0.05$ \\
\hline $\begin{array}{l}\text { Echocardiography: } \\
\text { LVEDD }\left(\mathrm{mm} / \mathrm{m}^{2}\right) \\
\text { FS }(\%) \\
\text { Blood volume }(\mathrm{l}) \\
\text { Serum sodium }(\mathrm{mmol} / \mathrm{l})\end{array}$ & $\begin{array}{cl}37 & (5) \\
11 & (4) \\
5 \cdot 8 & (1 \cdot 4) \\
140 & (2)\end{array}$ & $\begin{array}{cl}39 & (3) \\
11 & (3) \\
6 \cdot 3 & (1 \cdot 3) \\
142 & (2)\end{array}$ & $\begin{array}{l}\text { NS } \\
\text { NS } \\
\text { NS } \\
\text { NS }\end{array}$ \\
\hline
\end{tabular}
blood volume, and serum sodium 
Table 2 Haemodynamic measurements (mean (SD)) in the placebo and enalapril groups

\begin{tabular}{|c|c|c|c|c|c|c|c|c|}
\hline & \multicolumn{8}{|c|}{ Placebo group } \\
\hline & \multicolumn{2}{|c|}{$\frac{\text { Baseline }}{O h}$} & $2 h$ & & $3 h$ & & $5 h$ & \\
\hline $\begin{array}{l}\text { HR } \\
\text { RAP } \\
\text { MPAP } \\
\text { PCWP } \\
\text { MAP } \\
\text { CI } \\
\text { SVI } \\
\text { SVR } \\
\text { PVR } \\
\text { RPP }\end{array}$ & $\begin{array}{c}82 \\
4 \\
20 \\
11 \\
85 \\
2.5 \\
31 \\
1402 \\
159 \\
9422\end{array}$ & $\begin{array}{c}(14) \\
(3) \\
(8) \\
(8) \\
(9) \\
(0 \cdot 5) \\
(8) \\
(308) \\
(37) \\
(1729)\end{array}$ & $\begin{array}{c}81 \\
5 \\
19 \\
10 \\
81 \\
2 \cdot 8 \\
35 \\
1176 \\
144 \\
8914\end{array}$ & $\begin{array}{c}(11) \\
(3) \\
(6) \\
(7) \\
(9)^{\star} \\
(0 \cdot 5)^{\star \star} \\
(8)^{\star \star \star} \\
(245)^{\star \star \star} \\
(38)^{\star} \\
(1567)^{\star}\end{array}$ & $\begin{array}{c}82 \\
5 \\
19 \\
10 \\
80 \\
2 \cdot 7 \\
33 \\
1194 \\
136 \\
8915\end{array}$ & $\begin{array}{c}(8) \\
(4) \\
(5) \\
(6) \\
(12)^{\star} \\
(0 \cdot 6)^{\star} \\
(9) \\
(230)^{\star \star \star} \\
(46)^{\star \star} \\
(1605)^{\star}\end{array}$ & $\begin{array}{c}83 \\
5 \\
21 \\
12 \\
84 \\
2 \cdot 5 \\
30 \\
1371 \\
158 \\
9227\end{array}$ & $\begin{array}{c}(12) \\
(4)^{\star} \\
(8) \\
(8) \\
(10) \\
(0 \cdot 6) \\
(9) \\
(268) \\
(53) \\
(1621)\end{array}$ \\
\hline
\end{tabular}

Statistical differences within groups compared with baseline are indicated as ${ }^{\star} \mathrm{p}<0.05,{ }^{\star \star} \mathrm{p}<0.01,{ }^{\star \star \star} \mathrm{p}<0.001$

Statistical differences in changes from baseline between groups are indicated as $+p<0.05,+\dagger p<0.01$

HR, heart rate (beats/min); RAP, right atrial pressure (mm Hg); MPAP, mean pulmonary artery pressure (mm Hg); PCWP, pulmonary capillary wedge pressure (mm Hg); MAP, mean arterial pressure $(\mathrm{mm} \mathrm{Hg}) ; \mathrm{CI}$, cardiac index $\left(\mathrm{l} / \mathrm{min} / \mathrm{m}^{2}\right) ; \mathrm{SVI}$, stroke volume index $\left(\mathrm{ml} / \mathrm{m}^{2}\right) ; \mathrm{SVR}$, systemic vascular resistance (dyn.s.cm $\left.{ }^{-5}\right)$; PVR, pulmonary vascular resistance (dyn.s. $\left.\mathrm{cm}^{-5}\right)$; RPP, rate-pressure product (beats. $\left.\mathrm{mm} \mathrm{Hg} / \mathrm{min}\right)$.

HAEMODYNAMIC FUNCTION BEFORE AND AFTER MEALS IN THE PLACEBO GROUP

After the first meal (lunch), haemodynamic changes were greatest two and three hours after the start of the study (one and two hours after the meal) (table 2). Two hours after the start of the study (one hour after the meal, fig 1) mean arterial pressure $(-5(4) \%, p<0.05)$, systemic vascular resistance $(-16(9) \%, p<0.001)$, and the rate-pressure product $(-5(6) \%, p<0.05)$ were lower while the cardiac and stroke volume indices were higher $(12(8) \%, p<0.01$ and 13 (7) $\%, p<0.001$, respectively). Heart rate, right atrial pressure, mean pulmonary artery pressure, and pulmonary capillary wedge pressure were unchanged. These values returned to baseline five hours after the start of the study (four hours after the first meal); this indicated the start of the postabsorptive phase (fig 2). The changes after the second meal (dinner) were similar to those after the first one.

Fluctuations in haemodynamic variables not associated with eating were assessed by comparing estimates from postabsorptive determinations-that is at baseline and after five and 12 hours (fig 3). Compared with baseline values, right atrial pressure was increased after five hours while, in addition, after 12 hours heart rate, mean pulmonary artery and pulmonary capillary wedge pressures, cardiac index, and rate pressure product were also increased.

\section{HAEMODYNAMIC FUNCTION IN THE ENALAPRIL} GROUP

Serum concentrations of enalaprilat rose after only two hours $(20.4(9.8) \mathrm{ng} / \mathrm{ml}$ ) (fig 4).
Although the concentration was highest after four hours $(27.9(8.2) \mathrm{ng} / \mathrm{ml})$, the difference between two and five hours was not statistically significant. After five hours the serum concentrations fell, reaching $11.7(7.0) \mathrm{ng} / \mathrm{ml}$ after 12 hours. In the absorptive phase, after two and three hours, the changes in haemodynamic function resembled those in the placebo group. Compared with baseline values the mean arterial pressure, systemic vascular resistance, and rate-pressure product decreased $(-15$ (6) $\%, p<0.0001 ;-23(9) \%, p<0.001$; and $-12(13) \%, p<0.01$, respectively). The cardiac index and stroke volume index increased $(+14(9) \%, p<0.05$; and $17(15) \%$, $\mathrm{p}<0.01$, respectively). However, compared with placebo, the mean arterial pressure decreased more $(p<0.01)$ with enalapril, and after three hours the stroke volume index was increased $(p<0.05)$ and the rate-pressure product had fallen $(p<0.01)$. In contrast with the findings in the placebo group, pulmonary capillary wedge pressure decreased $(-24$ $(25) \%, p<0.01)$ and after three hours the heart rate $(-6(7) \%, p<0.05)$ was slower. The changes seen during the absorptive phase were maintained into the postabsorptive phase (that is five hours after the start of the study). Except for a further decrease in heart rate, no changes were found between two, three, and five hours.

Overall changes from baseline values during the 12 hour study period were computed as areas under the curve (fig 2). Compared with placebo, enalapril reduced heart rate $(p<0.05)$, pulmonary capillary wedge pressure $(p<0.05)$, mean arterial pressure $(p<0.01)$, and ratepressure product $(\mathrm{p}<0.01)$.
Figure 1 Mean (SD) and individual changes (mean at baseline and at two hours (one hour after the first meal)) in the placebo group. See table 2 for abbreviations.
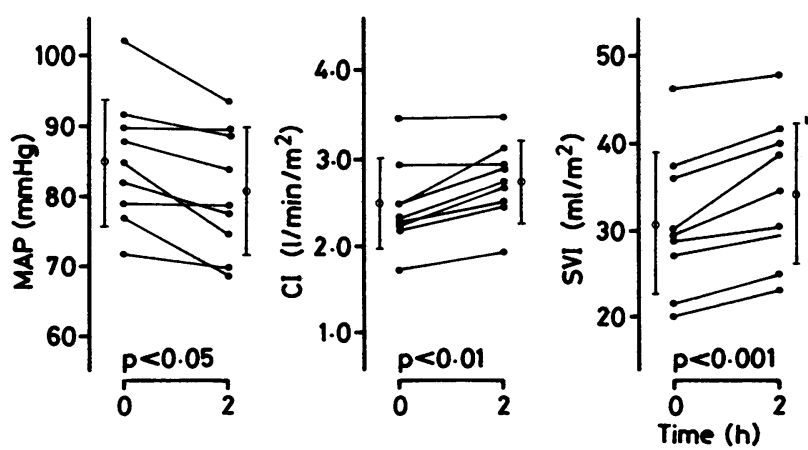


\begin{tabular}{|c|c|c|c|c|c|c|c|}
\hline \multicolumn{8}{|c|}{ Enalapril group } \\
\hline \multirow{2}{*}{\multicolumn{2}{|c|}{$\frac{\text { Baseline }}{O h}$}} & \multicolumn{4}{|c|}{ Absorptive phase } & \multirow{2}{*}{\multicolumn{2}{|c|}{$\frac{\text { Postabsorptive phase }}{5 h}$}} \\
\hline & & $2 h$ & & $3 h$ & & & \\
\hline $\begin{array}{c}87 \\
5 \\
25 \\
15 \\
83 \\
2 \cdot 3 \\
28 \\
1416 \\
174 \\
9833\end{array}$ & $\begin{array}{c}(20) \\
(3) \\
(7) \\
(7) \\
(7) \\
(0 \cdot 4) \\
(9) \\
(288) \\
(63) \\
(2077)\end{array}$ & $\begin{array}{c}85 \\
4 \\
22 \\
11 \\
71 \\
2 \cdot 6 \\
32 \\
1067 \\
187 \\
8522\end{array}$ & $\begin{array}{c}(18) \\
(2) \\
(5) \\
(4)^{\star \star} \\
(8)^{\star \star \star \dagger \dagger} \\
(0 \cdot 3)^{\star} \\
(9)^{\star \star} \\
(192)^{\star \star \star} \\
(44) \\
(1779)^{\star \star}\end{array}$ & $\begin{array}{c}81 \\
5 \\
22 \\
12 \\
69 \\
2 \cdot 5 \\
33 \\
1035 \\
187 \\
7774\end{array}$ & $\begin{array}{c}(19)^{\star} \\
(2) \\
(5) \\
(4)^{\star} \\
(8)^{\star \star \star \dagger} \\
(0 \cdot 3) \\
(9)^{\star \star \dagger} \\
(212)^{\star \star \star} \\
(48) \\
(1440)^{\star \star \star \dagger \dagger}\end{array}$ & $\begin{array}{c}80 \\
4 \\
22 \\
12 \\
70 \\
2 \cdot 4 \\
31 \\
1150 \\
168 \\
7687\end{array}$ & $\begin{array}{l}(15)^{\star \star} \\
(2)^{\dagger \dagger} \\
(5)^{\dagger} \\
(6)^{\star \dagger \dagger} \\
(6)^{\star \star \star}+\dagger \\
(0 \cdot 7) \\
(10)^{\star \dagger} \\
(223)^{\star \star} \\
(39)^{\star \star} \\
(978)^{\star \star \star \dagger \dagger}\end{array}$ \\
\hline
\end{tabular}

\section{Discussion}

This is the first placebo controlled, randomised double blind study showing the short term haemodynamic effects of an angiotensin-converting enzyme inhibitor in heart failure and the extent to which these effects are affected by eating, absorption, and postabsorption. In a group of patients with treated moderate heart failure caused by dilated cardiomyopathy, enalapril reduced left ventricular preload and afterload during both the absorptive and postabsorptive phases and hence throughout the 12 hour study period. Heart rate and the left ventricular metabolic cost, estimated as the rate-pressure product, decreased.

The principal features of central haemodynamic function during the absorptive phase (one hour after ingestion) were similar in controls and patients with varying degrees of heart failure. ${ }^{12-16}$ Systemic vascular resistance decreased with or without decreases in mean arterial blood pressure and heart rate while the cardiac index increased. These systemic effects reflect absorptive splanchnic hyperaemia and are the result of a locally mediated vascular response to digested nutrients in the lumen ${ }^{17}$ and their composition. ${ }^{18} 19$ The hyperaemia seems to be limited to tissues that are active in digestion and was maximal after 30-90 minutes when the local blood flow increased 30$150 \%$. $^{32021}$ In healthy individuals splanchnic hyperaemia was paralleled by an increase in renal blood flow, but this haemodynamic response to food seemed to be specific to proteinrich meals. ${ }^{22}$ Information on blood flow distribution to other vascular beds during the absorptive phase is scarce. Studies in animals suggest that blood flow to the brain and heart
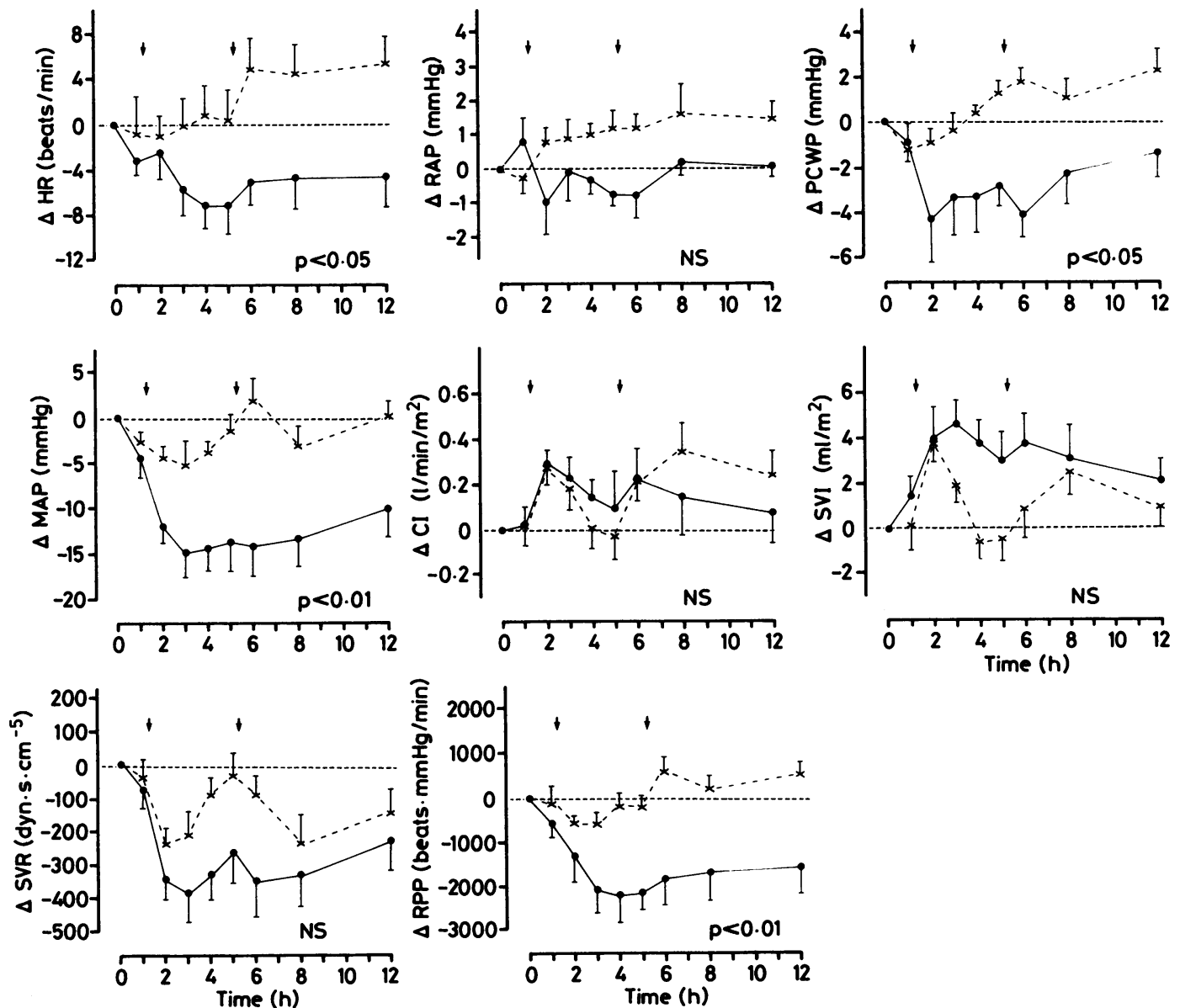

Figure 2 Absolute changes in haemodynamic measurements compared with baseline (mean (SEM)) after enalapril $(\bullet)$ and placebo $(\times)$. Arrows indicate meals. $p$ values indicate differences between the two groups in the respective areas under the curve calculated from zero. See table 2 for abbreviations. 

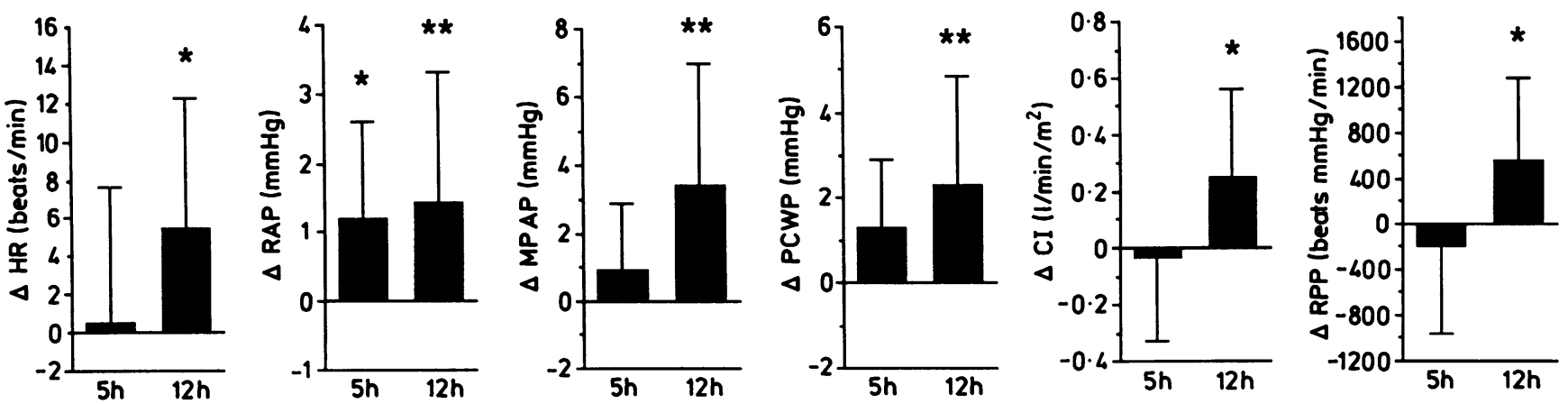

Figure 3 Spontaneous haemodynamic changes compared with baseline (mean (SD)) in the placebo group during postabsorptive phases at five and 12 hours. Significant differences from baseline as tested by analysis of variance are indicated as $\star_{p}<0.05$ and $\star_{p}<0.01$. See table 2 for abbreviations.

is unaltered and that to skeletal muscle is unaltered or reduced. ${ }^{21}$ Although the central haemodynamic changes during the absorptive phase are similar in individuals with or without varying degrees of heart failure, the distribution of blood flow to other organs may differ with the cardiac capacity.

Packer et $a l^{15}$ and Siemienczuk et $a l^{16}$ reported a decrease in pulmonary capillary wedge pressure during the absorptive phase in patients with heart failure, but we found no change. This difference might be because our patients had a lower filling pressure. Differences in the selection of patients, study design, and spontaneous haemodynamic changes may be relevant.

We did not standardise the amount and composition of the meals eaten by our patients, who ate as much as they wanted and probably the same as they normally did.

In the placebo group we saw increases in heart rate, pressures, and cardiac index after 12 hours and in the postabsorptive phase. These results are at variance with those reported by Packer et al, who found a gradual decrease in pulmonary capillary wedge pressure during 24 hours after right heart catheterisation. ${ }^{15}$ Massie et al reported similar results. ${ }^{23}$ In contrast, we found increases in right atrial and pulmonary capillary wedge pressures after 12 hours and in the postabsorptive state, but we did not stop diuretics on the day of investigation. Diuresis during the morning could have added to lower filling pressures at baseline. Such differences in basal haemodynamic conditions underscore the importance of well defined basal conditions in order to avoid bias introduced by the design of a clinical trial.

Two hours after the oral administration of

Figure 4 Concentration curve of serum enalaprilat (mean $(S D)$ ).
$10 \mathrm{mg}$ of enalapril the serum concentration of enalaprilat was $20 \cdot 4(9 \cdot 8) \mathrm{ng} / \mathrm{ml}$. After 12 hours it was $11.7(7.0) \mathrm{ng} / \mathrm{ml}$. The serum concentration curve resembled that found in controls ${ }^{6}$ and the time to peak concentration was not delayed, as has been reported in severe heart failure. ${ }^{24}$ Angiotensin-converting enzyme inhibition in the $90 \%$ range was reported at only $10 \mathrm{ng} / \mathrm{ml} .^{25}$. Therefore, angiotensinconverting enzyme inhibition was likely to be effective from the second to the twelfth hour of this study.

During the absorptive phase the reduction of afterload was more pronounced with enalapril than with placebo. Though the reduction of afterload during the absorptive phase in the placebo group was transient, it was maintained into the postabsorptive phase after enalapril. In addition, enalapril reduced heart rate and preload as expressed by a decreased pulmonary capillary wedge pressure while no change was seen in the placebo group. These enalapril induced changes increased from recordings during the absorptive phase to those of the postabsorptive phase, in keeping with short term pharmacodynamic studies on heart failure in which maximal haemodynamic effects, including heart rate and afterload reduction, were seen 4-8 hours after administration of a single oral dose. ${ }^{6}$ So we would not expect the maximal afterload reduction in the enalapril group to occur as early as two and three hours after administration. Indices measured after two and three hours, however, resembled those measured five hours after administration. This indicates that after two and three hours, during the absorptive phase, the total reduction of afterload is a summation of enalapril-induced and meal-induced vasodilatation.

The patients were given diuretics on the day of investigation and this may have potentiated the haemodynamic changes produced by enalapril owing to complex interactions between diuretics and converting enzyme inhibitors. ${ }^{26}$ Notwithstanding this fact, the aim of the study was to describe the short term haemodynamic effects of enalapril in an experimental situation that resembled, as far as possible, the daily routine of the patient at rest. In addition to meals, this routine also includes a continuation of long term medication.

In short term studies of congestive heart failure, inhibition of angiotensin-converting enzyme activity reduced systemic arterial pressure and systemic peripheral resistance and 
increased the cardiac index. In most vascular beds (limbs, ${ }^{27-29}$ brain, ${ }^{30}$ liver, ${ }^{29}$ and coron$\operatorname{aries}^{2731}$ ) tissue flow is maintained through homoeostatic vasodilatation. Information on splanchnic blood flow was ambiguous. The increase in the cardiac index was directed mainly to the kidneys where the regional blood flow was increased. ${ }^{27} 29$ During the absorptive phase splanchnic vasodilatation induced by enalapril was supplemented by physiological splanchnic vasodilatation, which was probably caused by regionally active vasodilating agents.

\section{CONCLUSIONS}

(a) The principal haemodynamic effects of eating and absorption seemed to be similar in controls and patients with varying degrees of heart failure. After a meal there was a transient reduction of afterload and an increase in cardiac index. (b) When meals were being eaten regularly angiotensin-converting enzyme inhibition by enalapril in patients with moderate heart failure caused by dilated cardiomyopathy produced signs of a balanced reduction in preload and afterload with a decreased rate-pressure product. The afterload reduction was additional to that induced by meals. (c) To avoid bias in clinical trials the study design should be double blind with well controlled basal conditions.

This study was supported by funds from the Karolinska Institute and the Swedish Heart and Lung Foundation.

1 Grollman A. Physiological variations in the cardiac output of man. III. The effect of the ingestion of food on the cardiac man. III. The effect of the ingestion of food on the cardiac output, pulse rate, blood pressure and oxygen

2 Burns GP, Schenck WG. Effect of digestion and exercise on intestinal blood flow and cardiac output. Arch Surg 1969;98:790-4.

3 Norryd C, Denker H, Lunderquist A, Olin T, Tylen U. Superior mesenteric blood flow during digestion in man Acta Chir Scand 1975;141:197-202.

4 Francis GS. Neuroendocrine manifestations of congestive heart failure. Am J Cardiol 1988;62:9A-13A.

5 Romankiewicz JA, Brogden RN, Heel RC, Speight TM, Avery GS. Captopril: an update review of its pharmacological properties and therapeutic efficacy in congestive heart failure. Drugs 1983;25:6-40.

6 Todd PA, Heel RC. Enalapril. A review of its pharmacodynamic and pharmacokinetic properties and therapeutic use in hypertension and congestive heart failure. Drugs 1986;31:198-248.

7 Swanson BN, Vlasses PH, Ferguson RK, et al. Influence of food on the bioavailability of enalapril. J Pharm Sci 1984;73:1655-7.

8 Patterson JA, Naughton J, Pietras RJ, Gunnar RM. Treadmill exercise in assessment of the functional capacity of patients with cardiac disease. Am J Cardiol 1972;30: patients

9 Sahn DJ, DeMaria A, Kisslo J, Weyman A. Recommenda- tions regarding quantitation in m-mode echocardiography: results of a survey of echocardiographic measurements. Circulation 1978;58:1072-83.

10 Jonsell S. A method for the determination of the heart size by teleroentoenography (a heart volume index). Acta Radiologica 1939;20:325-40.

11 Hichens M, Hand EL, Mulcahy WS. Radioimmunoassay for angiotensin converting enzyme inhibitors [Abstract]. Ligand Quarterly 1981;4:43.

12 Fagan TC, Sawyer PR, Gourley LA, Lee JT, Gaffney TE Postprandial alterations in hemodynamics and blood pressure in normal subjects. Am J Cardiol 1986;58: 636-41.

13 Jarvis RC, Green JA, Nara AR, Pospisil R, Kasmer RJ. Effects of food ingestion on hemodynamics in chronic congestive heart failure. Crit Care Med 1988;16:491-4.

14 Cornyn JW, Massie BM, Unverferth DV, Leier CV. Hemodynamic changes after meals and placebo treatmen in chronic congestive heart failure. Am J Cardiol 1986; 57:238-41.

15 Packer M, Medina N, Yushak M. Hemodynamic changes mimicking a vasodilator drug response in the absence of drug therapy after right heart catheterization in patients with chronic heart failure. Circulation 1985;71:761-6.

16 Siemienczuk D, Greenberg B, Broudy DR. Effects of eating on cardiac performance in congestive heart failure. Chest 1986;90:193-7

17 Gallavan RH, Chou CC. Possible mechanisms for the initiation and maintenance of postprandial intestinal hyperemia. Am J Physiol 1985;249:G301-8.

18 Brandt JL, Castleman L, Ruskin HD, Greenwald JJ, Kelly $\mathrm{J}$. The effect of oral protein and glucose feeding on splanchnic blood flow and oxygen utilization in normal splanchnic blood flow and oxygen utilization in normal
and cirrhotic subjects. J Clin Invest 1955;34:1017-25.

19 Siregar H, Chou CC. Relative contribution of fat, protein, carbohydrate and ethanol to intestinal hyperemia. $\mathrm{Am}$ J carbohydrate and ethanol

20 Gallavan RH, Chou CC, Kvietys PR, Sit SP. Regional blood flow during digestion in the conscious dog. Am J Physiol 1980;238:H220-5.

21 Chou CC. Splanchnic and overall cardiovascular hemodynamics during eating and digestion. Fed Proc 1983;42:1658-61.

22 Premen AJ. Protein-mediated elevations in renal hemodynamics: existence of a hepato-renal axis? Med Hypotheses 1986;19:295-309.

23 Massie BM, Leier CV, Unverferth DV. Hemodynamic changes following placebo administration: implication for drug studies [Abstract]. Circulation 1984;70(supp II): 112 .

24 Dickstein $\mathrm{K}$, Till AE, Aarsland $\mathrm{T}$, et al. The pharmacokinetics of enalapril in hospitalized patients with congestive heart failure. Br J Clin Pharmacol 1987;23:403-10.

25 Biollaz J, Schelling JL, Jacot des Combes B, Brunner DB Desponds G, Brunner HR. Enalapril maleate and a lysine analogue (MK-521) in normal volunteers; relationship between plasma drug levels and the renin angiotensin between plasma drug levels and the renin
system. Br J Clin Pharmacol 1982;14:363-8.

26 Cleland JG, Gillen G, Dargie HJ. The effects of frusemide and angiotensin-converting enzyme inhibitors and their and angiotensin-converting enzyme inhibitors and their combination on cardiac and renal haem

27 Faxon DP, Creager MA, Halperin JL, Bernard DB, Ryan TJ. Redistribution of regional blood flow following angiotensin-converting enzyme inhibition. Comparison of normal subjects and patients with heart failure. $A m J$ Med 1984;76:104-10.

28 Levine TB, Olivari MT, Cohn JN. Hemodynamic and regional blood flow response to captopril in congestive heart failure. Am J Med 1984;76:38-42.

29 Levine TB, Olivari MT, Garberg V, Sharkey SW, Cohn JN Hemodynamic and clinical response to enalapril, a longacting converting-enzyme inhibitor, in patients with congestive heart failure. Circulation 1984;69:548-53.

30 Paulson OB, Jarden JO, Vorstrup S, Holm S, Godtfredsen J. Effect of captopril on the cerebral circulation in chronic heart failure. Eur J Clin Invest 1986;16:124-32.

31 De Marco T, Daly PA, Liu M, Kayser S, Parmley WW, Chatterjee K. Enalaprilat, a new parenteral angiotensinChatterjee $K$. Enalaprilat, a new parenteral angiotensinconverting enzyme inhibitor: rapid changes in systemic chronic heart failure. J Am Coll Cardiol 1987;9:1131-8. 